\title{
РИСКИ И ВОЗМОЖНОСТИ РОССИЯН КАК БАЗА СОЦИАЛЬНОЙ ДИНАМИКИ
}

Один из центральных вопросов социальной политики- контроль за уровнем и глубиной неравенств. Самый простой, а поэтому и наиболее распространенный для оценки вариант их проявлений-дифференциация доходов. Однако изучение социального неравенства также требует оценки рисков и возможностей населения через доступность для него значимых социальных благ и ресурсов. Именно они генерируют те жизненные шансы россиян, которые либо требуют инструментов компенсации мерами социальной поддержки, являясь своеобразными вызовами для нее, либо открывают дополнительные «окна возможностей» не только для самого населения, но и для разворачивания государственной политики инвестиционного характера. В статье на репрезентативных общероссийских данных Мониторинга ИС ФНИСЦ РАН при использовании веберианской логики жизненных шансов и негативной/позитивной привилегированности в связи с их комбинацией продемонстрированы основные риски и возможности населения в части (1) экономических условий жизни, (2) особенностей потребления и досуга, (3) ситуации на работе, (4) возможности получения образования и сохранения здоровья. Показано, что позитивная привилегированность обеспечивается, в первую очередь, через возможности в сфере потребления и экономические условия жизни, а негативная - через положение россиян в производственной сфере. Подобное состояние жизненных шансов населения свидетельствует об ограниченности потенциала встраиваться в технологические сценарии развития страны, которые основаны на человеческом капитале как основном средстве производства. Жители столиц, уже освоив практики активного товарного потребления, заметно отличаются от остального населения, которое только перенимает соответствующие образцы поведения. Следующая сфера, которая осваивается россиянами- навыки существования

Юлия Павловна Лежнина- к.с.н., старший научный сотрудник, Институт социальной политики, Национальный исследовательский университет «Высшая школа экономики»; ст. н.с., ФНИСЦ ИС РАН, Москва, Россия. Электронная почта: lezhnina@list.ru 
в цифровой среде. При этом даже у москвичей и петербуржцев риски, с которыми они, как и остальное население, сталкиваются в сфере занятости, выступают заметным ограничителем позитивной динамики человеческого потенциала на перспективу. Негативная привилегированность чаще всего локализуется в сельской местности, а в производственной сфере даже становится нормой состояния населения для этого типа поселений.

Ключевые слова: жизненные шансы, риски, возможности, территориальное неравенство, пространственная неоднородность

DOI: 10.17323/727-0634-2019-17-2-207-222

Проблематика неравенства является ключевой для общественных наук, а проявления неравенств на практике всегда в фокусе социальной политики. Неравенства и методики их измерения носят крайне разнообразный характер (Мареева 2016), но в целом первенство по распространенности исследований традиционно отводится экономическому неравенству. Самые популярные подходы к анализу неравенства связаны с доходами (подробный обзор см.: Аникин, Лежнина 2018), расходами как показателями характеристик потребления (напр., Banerjee, Duflo 2008), а также накопленным богатством (напр., Credit Suisse Research Institute 2015). Однако монетарные измерения экономического положения, даже если они построены на относительных показателях, не дают достоверного представления о том, какие реальные возможности есть у населения с тем или иным статусом. Картина экономического благополучия становится более ясной, когда она дополняется характеристиками особенностей потребления, условий жизни, специфики занятости. При этом группы с максимальными депривациями в этих сфеpax- это точки локализации вызовов для социальной политики. Они требуют внимания государства и привлечения экономических ресурсов для решения проблем соответствующих социальных групп: плохого материального положения, социальной эксклюзии, дискриминации на работе. Группы с наибольшими возможностями- ресурсные центры. Они локализуют активы в объеме, превышающем их основные потребности, а соответственно могут выступать акторами и донорами социальной политики в отношении себя и своего окружения.

В этой связи для России изучение характеристик жизненных шансов населения крайне актуально, т.к. вектор дальнейшего развития как социальной политики, так и социально-экономической системы в целом в настоящее время не определен. При этом в нашей стране, для которой ключевым фактором экономического неравенства является пространственная неоднородность (Овчарова и др. 2016), отдельный вопрос вызывает территориальная неравномерность распределения жизненных шансов населения в части соответствующих рисков и возможностей. Их конфигурация в пространстве 
позволяет определить «болевые точки», которые требуют государственного внимания. Этому вопросу и посвящена статья.

В качестве эмпирической базы исследования использованы данные шестой и третьей волн Мониторинга ИС ФНИСЦ РАН «Динамика социальной трансформации современной России в социально-экономическом, политическом, социокультурном и этнорелигиозном контекстах», проведенных в мае 2017 г. и октябре 2015 г. соответственно. Выборка составляла 4 тыс. респондентов, репрезентирующих взрослое население страны в возрасте 18 лет и старше по основным социально-демографическим показателям (подробнее см.: Петухов 2018).

\section{Риски и возможности как система жизненных шансов}

Изучение неравенств и систем стратификации через призму рисков и возможностей, а также вопросов их справедливости нашло широкое распространение в социальных исследованиях. Их зарождением можно назвать работы Макса Вебера (Weber 1978), который трактовал жизненные шансы (lebenschancen) как причину и следствие социального положения, определяемого через уровень знаний и компетенций, потребление тех или иных благ и престиж/уважение. При этом по совокупности жизненных шансов Вебер выделял позитивную и негативную привилегированность как состояния относительно высоких и низких возможностей соответственно. Впоследствии эта логика получила свое развитие в работах плеяды ученых (Beck 2009; Scott 2002; Eitzen, Zinn 1989; Goldthorpe et al. 1987; Giddens 1973). Уточнению и модификации подвергались и формулировки терминов: от capabilities и functionings Амартия Сена (Sen 1992) до доступности редких и ценных благ Ричарда Брина (Breen 2005) и возможности выбирать желаемый образ жизни и жить той жизнью, которую они ценят у Гарри Брайхауса и Ингрид Робейнс (Robeyns, Brighouse 2010), а также трактовки понятий, и набор доменов, значимых для интеграции жизненных шансов.

Опыт эмпирических исследований рисков и возможностей, в том числе в работах отечественных авторов, содержит как анализ состояния отдельных сфер повседневности (Рopova, Pishnyak 2017; Тихонова и др. 2004), так и попытки выстраивания схемы возможностей и рисков населения с опциональным последующим иерархизированием соответствующих позиций (Тихонова 2018). Большой интерес ученых к изучению жизненных шансов и накопленный багаж теоретических и эмпирических работ позволяют определить основные сферы, которые рассматриваются для их описания (Anikin et al. 2017).

В обществах позднего индустриального типа точкой наиболее острых неравенств рассматривается экономическая сфера, а их проявления раскрываются через возможности и риски в области «экономической безопасности», потребления, и производственной среды. Для современных обществ, 
которые находятся на пост- или позднем индустриальном этапе развития, неравенства также характерны в сферах получения образования и сохранения здоровья как источниках наращивания основного производственного ресурса - человеческого капитала.

\section{Риски и возможности: «кому на Руси жить хорошо»?}

\section{Экономические условия жизни}

Типичные текущие условия жизни россиян, несмотря на общую благополучность в повседневности, не предполагают наличия ресурсов для решения ситуационных проблем или реализации инвестиционных инициатив. Так, абсолютное большинство оценивает как «хорошие» или «удовлетворительные» свои возможности питаться (95\%), одеваться (91 \%), жилищные условия (91 \%), а также возможности проведения досуга (85\%) и материальное положение в целом (79\%); имеет в собственности квартиру или дом (91\%), а средняя жилплощадь, приходящаяся на одного члена семьи составляет 22,2 кв.м., что превышает социальную норму жилищной обеспеченности (18 кв.м.). Помощь от друзей, родственников, соседей как основной источник дохода отмечают только $10 \%$ россиян. При этом наличие иного объекта недвижимости в виде дачи или участка с домом и автомобиля для комфортного использования этих объектов уже создает основания для «позитивной привилегированности» и является индикатором повышенных экономических возможностей в повседневной жизни (табл. 1), т.к. ими обладает менее пятой части (22\%) населения страны. Стоит отметить, что жители столиц демонстрируют соответствующие возможности в 2 раза чаще остальных. С одной стороны, такая ситуация обусловлена особенностями проживания в крупном населенном пункте: перемещение на большие расстояния становится заметно комфортнее при наличии собственного транспорта, а влияние плохой экологии частично компенсируется периодическим отдыхом за чертой города. Однако соответствующий образ жизни требует дополнительных расходов на содержание автомобиля и дачи, поэтому для столиц, как и для остальной России, наличие обозначенной совокупности дорогостоящего имущества в целом не является нормой. Ресурсный запас населения в виде инвестиций или сбережений, способных обеспечить жизнь семьи не менее чем на год, а также наличие второго жилья (квартиры или дома) - это те условия жизни, которые доступны уже только 4-11\% населения в разных типах поселений. При этом столицы, хотя и отличаются максимальными значениями этих показателей, не демонстрируют большого отрыва от других населенных пунктов.

В итоге по совокупности возможностей в экономической сфере жители столиц принципиально отличаются от остального населения: для них 
типичным (51\%) является наличие хотя бы одного из признаков привилегированности (табл. 1), в то время как для населения остальной России соответствующий показатель составляет менее трети (22-29\%); более одного признака привилегированности имеют $12 \%$ населения столиц и только 2-6\% россиян, проживающих вне Москвы и Петербурга. При этом такие риски, связанные с экономическими условиями жизни, как множественные или крупные долги/кредиты, наличие дополнительных неэластичных расходов (например, на лекарства), а также нестабильность доходов (сезонная, временная занятость, приработки при отсутствии постоянного места работы) свойственны для $12 \%$ россиян.

Таблица 1

Распространенность признаков рисков и возможностей в экономической сфере среди россиян из населенных пунктов разного типа, ИС ФНИСЦ РАН, 2017 (\%)

\begin{tabular}{|c|c|c|c|c|c|}
\hline & 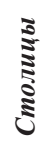 & 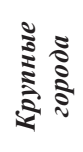 & 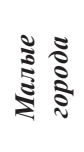 & 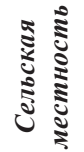 & 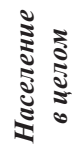 \\
\hline \multicolumn{6}{|c|}{ Возможности/позитивная привилегированность } \\
\hline Наличие второго жилья & 7 & 7 & 4 & 4 & 5 \\
\hline Наличие иной недвижимости и автомобиля & 47 & 20 & 18 & 18 & 22 \\
\hline $\begin{array}{l}\text { Наличие иных инвестиций и сбережений, } \\
\text { обеспечивающих долгосрочное проживание }\end{array}$ & 11 & 10 & 5 & 8 & 8 \\
\hline
\end{tabular}

Риски/негативная привилегированность

\begin{tabular}{l|r|r|r|r|r}
\hline $\begin{array}{l}\text { Наличие множественных или крупных } \\
\text { долговых обязательств }\end{array}$ & 8 & 10 & 12 & 10 & 10 \\
$\begin{array}{l}\text { Наличие неэластичных или крупных } \\
\text { дополнительных расходов помимо долговых } \\
\text { обязательств }\end{array}$ & 4 & 4 & 4 & 6 & 5 \\
Нестабильность доходов & 4 & 5 & 1 & 4 & 3 \\
\hline
\end{tabular}

* В таблице приведены показатели, учитывающие потребность членов семьи в лекарствах, однако были недоступны данные о наличии иных неэластичных расходов, например, на аренду жилья.

Хотя бы один из рассматриваемых признаков негативной привилегированности в экономической сфере (табл. 1) есть в наличии у 16-19\% населения в зависимости от места проживания, более одного встречаются достаточно редко- до 1,5\% у жителей сельской местности. Таким образом, риски неблагополучных экономических условий жизни не имеют строгой пространственной привязки, как, впрочем, и общей распространенности, 
в то время как возможности в этой сфере у населения столиц заметно выше, чем у остального населения. Объем экономических ресурсов россиян, достаточный для формирования подушки безопасности на период нестабильности, источника пассивного дохода или стартового капитала для инициатив, доступен, по большому счету, лишь жителям столиц. Это выводит Москву и Санкт-Петербург в точки-лидеры по потенциалу населения реагировать на изменения экономической среды: купировать последствия экономических шоков на микроуровне и инвестировать в появляющиеся «окна возможностей» в трансформирующейся повседневности. Более того, в части этих возможностей столицы буквально противопоставлены остальной России.

\section{Особенности потребления и досуга}

Повседневные практики потребления и проведения досуга свидетельствуют о том, насколько свободными в распоряжении финансовыми ресурсами являются россияне. Типовой ситуацией для российского населения является наличие в распоряжении набора из семи товаров длительного пользования (ТДП) по медиане (из 15 проверявшихся в опросе, включая телевизор, холодильник, пылесос, кухонную технику и телефон/ смартфон, компьютерную технику, гаджеты, в том числе фото- и видеотехнику, а также такие редкие и престижные товары домашнего использования как кондиционер или посудомоечная машина). Наиболее распространенными из них являются холодильник, телевизор, пылесос, стиральная машина-автомат (91-99\%), а также иная бытовая техника (84\%) и мобильные телефоны (81\%). Больше половины россиян (57\%) удовлетворительно оценивают свои возможности проведения досуга.

О позитивной привилегированности в сфере потребления свидетельствуют «хорошие» возможности проведения отпуска, что всегда требует дополнительных ресурсов, о таковых говорят 14-19\% жителей различных населенных пунктов (табл. 2). Очень маленькая доля населения - 4-6\%проживает в особенно комфортных условиях - в жилье с коммунальными удобствами и площадью, превышающей социальную норму (по норме, 36 кв.м. на человека, проживающего отдельно, с добавлением 18 кв.м. на каждого последующего члена семьи). Наиболее часто относительная благополучность в сфере потребления и досуга проявляется через расширенное по отношению к населению в целом стилевое товарное потребление с включением в состав располагаемых ТДП дополнительных к стандартному количеству элементов (более 1,25 медианы), включая редкие и престижные. Этот тип привилегированности хотя бы в одном из трех рассматриваемых ее проявлений (жилье, досуг и отдых, товарное потребление) демонстрируют более трети (34\%) россиян, опять же, как и возможности в экономической сфере. При этом для столиц расширенные возможности товарного потребления являются нормой (51\%). 
Таблица 2

Распространенность признаков рисков и возможностей в сфере потребления и досуга среди россиян из населенных пунктов разного типа, ИС ФНИСЦ РАН, 2017 (\%)

\begin{tabular}{|c|c|c|c|c|c|}
\hline & 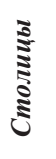 & 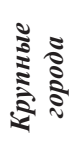 & 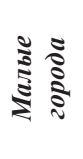 & 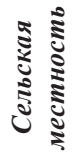 & 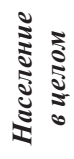 \\
\hline \multicolumn{6}{|l|}{ Возможности/позитивная привилегированность } \\
\hline Хорошие возможности проведения отпуска & 14 & 19 & 16 & 14 & 16 \\
\hline $\begin{array}{l}\text { Возможность расширенного стилевого } \\
\text { товарного потребления }\end{array}$ & 51 & 41 & 31 & 24 & 34 \\
\hline Особая комфортность жилищных условий & 4 & 6 & 4 & 4 & 5 \\
\hline \multicolumn{6}{|l|}{ Риски/негативная привилегированность } \\
\hline Пищевые депривации & 9 & 7 & 8 & 7 & 8 \\
\hline Суженный стандарт предметного потребления & 6 & 11 & 17 & 24 & 16 \\
\hline $\begin{array}{l}\text { Низкий стандарт жилищных условий в месте } \\
\text { проживания }\end{array}$ & 5 & 16 & 14 & 19 & 15 \\
\hline
\end{tabular}

Негативная привилегированность россиян в сфере потребления и досуга опять же в основном формируется через обеспеченность ТДП (их наличие в количестве менее 0,75 медианы). Ее демонстрируют $16 \%$ россиян. Относительно чаще она концентрируется в сельской местности (24\%), а реже- в Москве и Петербурге (6\%). В столицах большая доля населения сталкивается с пищевыми депривациями- плохим питанием (9\%), что реже встречается в остальной России (7-8\%). Это, видимо, является спецификой экономической жизни столиц с нехваткой времени у работающего населения на приготовление качественной домашней пищи и высокими ценами на общественное питание. При этом жители Москвы и Санкт-Петербурга относительно редко сталкиваются с низкими стандартами жилищных условийтолько $5 \%$ из них не имеют коммунальных удобств в своем жилье или площадь последнего менее 12 кв.м. на человека, в то время как для остального населения соответствующий показатель равен 14-19\%. Это связано, с одной стороны, с общим качеством коммунальной инфраструктуры столиц, a, с другой стороны, меньшим по сравнению с остальной Россией, размером их домохозяйств (в среднем 2,69 человек и 2,82-3,06 соответственно).

Таким образом, как риски, так и возможности россиян в сфере потребления и досуга сводятся в основном к товарному потреблению в относительно меньшем или большем объеме по сравнению с остальным населением. Их доминирование наряду с наличием статистически значимых показателей наличия пищевых деприваций свидетельствует о том, 
что реализация запросов на товарно-досуговое потребление находится в стадии своего «становления». Иными словами, потребительская культура большей части населения страны только формируется, и ее спецификой сегодня является не столько разумное потребление с ориентацией на его целесообразность в долгосрочной перспективе, сколько получение текущей удовлетворенности локальных потребностей. Этому способствует как продолжительные периоды товарного дефицита и ограниченности ресурсов, с которыми сталкивалась большая часть россиян на протяжении своей жизни, так и текущие экономические ограничения населения для проявления инвестиционно-ориентированного и часто относительно дорогостоящего поведения.

\section{Ситуация на работе}

Для российского общества производственная сфера играет ключевую роль в определении жизненных шансов населения. Несмотря на то, что рабочее место сегодня, в отличие от советского периода, уже не является точкой, через которую осуществляется доступ к значимым ресурсам и объектам потребления, именно через занятость и трудовые доходы в первую очередь обеспечивается текущий уровень жизни, поддерживается доступность тех или иных желаемых социальных благ. Зарплата по основному месту работы входит в число основных источников дохода для трех четвертей населения (70-80\% в зависимости от места проживания), совместительство и разовые приработки имеют еще 6\% (5-11\%) и 19\% (16-29\%) россиян соответственно.

Ситуация с занятостью и работой скорее свидетельствует о преобладании проявлений негативной привилегированности над позитивной (табл. 3). Так, треть (34\%) россиян или половина (49\%) работающих говорили в 2017 г. о том, что в отношении них работодатель не соблюдает трудовое законодательство (официальное оформление на работу, обеспечение «белой» зарплаты, оплата отпуска и больничного листа). При этом в сельской местности наличие таких нарушений является скорее нормой, чем исключением (58\% для работающих). Еще для четверти (26\%) работающих россиян (18\% населения в целом) занятость сопряжена с такими неблагоприятными условиями как неоплаченные сверхурочные при наличии перегрузок, для работающих жителей сел и ПГТ этот показатель достигал 31 \%. И даже при этом $17 \%$ работающих сталкивались с рисками безработицы- в течение трех лет перед опросом 2017 г. попадали в ситуации, когда нигде не работали и не учились более трех месяцев подряд.

Если же говорить о позитивной привилегированности в отношении ситуации на работе, то она формируется чаще всего за счет минимизации эффекта отчуждения в труде по месту работы. Так, например, треть работающих (36\%) способны повлиять на принятие решения в масштабах всего предприятия, на котором они работают, или своего подразделения. В 2015 г. 
$27 \%$ занятых отмечали, что сами принимают решение о том, какие задания выполнять или как изменить темп работы, когда выйти в отпуск и брать отгул, когда приходить на работу и уходить с нее. В несколько отличном на общем фоне положении находятся жители столиц. Среди них об умеренности эффекта отчуждения в труде через наличие ресурса влияния на решения в масштабах предприятия или подразделения говорят $45 \%$, в то время как для всех остальных этот показатель составляет около трети (32-38\%).

Таблица 3

Характеристики ситуации на работе среди россиян из населенных пунктов разного типа, ИС ФНИСЦ РАН, 2017 (\%)*

\begin{tabular}{|c|c|c|c|c|c|}
\hline & $\underset{3}{3}$ & 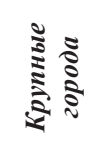 & 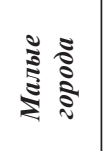 & 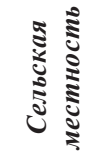 & 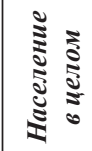 \\
\hline \multicolumn{6}{|c|}{ Возможности/позитивная привилегированность } \\
\hline $\begin{array}{l}\text { Отсутствие или минимизация эффекта } \\
\text { отчуждения в труде по месту работы }\end{array}$ & $33(45)$ & $23(38)$ & $24(32)$ & $25(36)$ & $25(36)$ \\
\hline $\begin{array}{l}\text { Наличие работы, являющейся объектом } \\
\text { желаний россиян }\end{array}$ & $11(15)$ & $11(19)$ & $15(20)$ & $14(20)$ & $13(19)$ \\
\hline $\begin{array}{l}\text { Наличие дополнительных благ по месту } \\
\text { занятости }\end{array}$ & $7(10)$ & $6(10)$ & $7(9)$ & $5(6)$ & $6(9)$ \\
\hline \multicolumn{6}{|l|}{ Риски/негативная привилегированность } \\
\hline $\begin{array}{l}\text { Риски безработицы (состояние безработицы } \\
\text { на протяжении } 3 \text { месяцев за последние } 3 \text { года } \\
\text { или в текущий момент) }\end{array}$ & $10(11)$ & $13(18)$ & $13(15)$ & $20(21)$ & $15(17)$ \\
\hline Несоблюдение законодательства на работе & $30(42)$ & $26(43)$ & $36(47)$ & $41(58)$ & $34(49)$ \\
\hline Неблагоприятные условия занятости** & $20(28)$ & $13(22)$ & $18(24)$ & $21(31)$ & $18(26)$ \\
\hline
\end{tabular}

* В скобках представлены значения для работающего населения

** В данном случае- неоплачиваемые перегрузки при рабочем дне продолжительностью не менее 45 часов в неделю. Данные использованных массивов не позволили оценить наличие задержек зарплаты, вынужденную занятость на неполный рабочий день и т.д.

При этом среди работающих россиян только 19\% удовлетворены содержанием своего труда и возможностями сделать карьеру, что свидетельствует об их позитивной привилегированности в части наличия желаемой работы относительно остального населения. В целом более половины работающих (53\%) не рассматривают работу как желаемую, среди обладающих ресурсом влияния на работе таковых $32 \%$. В столицах эти показатели еще ниже и составляют треть (33\%) и четверть (26\%) соответственно. При этом формализованные дополнительные привилегии в виде жилья, транспорта, медицинской помощи, питания, кредитов предоставляются только $9 \%$ 
работающих россиян, среди располагающих ресурсом влияния таковых $12 \%$, а среди тех, чья работа является желаемой, $17 \%$.

Таким образом, формирование позитивной привилегированности производственной ситуации происходит в основном за счет наличия возможности влиять на принятие решений на работе, нежели за счет объективных дополнительных благ и потенциально материализуемых бонусов, и доступно оно в основном жителям столиц. Риски же для россиян в производственной сфере обусловлены тем, что текущее состояние рынка труда можно охарактеризовать скорее как рынок работодателя, что позволяет последнему эксплуатировать работников и не соблюдать их трудовые права. В наиболее уязвимом положении находятся россияне сельских населенных пунктов, включая ПГТ, для которых несоблюдение базовых трудовых гарантийскорее норма, чем исключение, т.к. именно локальные рынки труда недостаточно развиты и не создают работникам пространства для наращивания переговорных позиций в диалоге с работодателями.

\section{Возможности получения образования и сохранения здоровья}

Еще одна сфера, которая в условиях наращивания значимости человеческого капитала как средства производства оставляет простор для формирования неравенства- получение образования и сохранение здоровья. На текущий момент типовая ситуация состояния здоровья населения-его удовлетворительная самооценка (59\%) и наличие возможности получения качественной медицинской помощи (56\%). В части квалификационных характеристик человеческий капитал большинства населения (62\%) формируется за счет образования не выше среднего специального без постоянного повышения квалификации (за последние три года $58 \%$ россиян никак не пополняли свои знания). В этой связи позитивная привилегированность формируется уже за счет возможности монополизировать преимущества социально привлекательных видов образования- через использование платных образовательных услуг для взрослых и детей (табл. 4), к чему прибегали в том или ином виде в течение трех лет перед опросом $24 \%$ россиян, навыков существования в цифровой среде, например, ежедневного использования в работе интернета $(16 \%)$, а также хорошей доступности качественной медицинской помощи (9\%).

В столицах самый низкий показатель пополнения знаний за счет использования платных образовательных услуг. Подобная ситуация складывается, с одной стороны, в связи с тем, что в силу перегрузок на работе и темпа жизни столиц на дополнительное образование у их жителей не остается времени: отработанное за неделю время составляет 41 час, при этом для жителей столиц соответствующий показатель равен 45 часам, а для всех остальных россиян - 40 часам. С другой стороны, рынок труда столиц разнообразен и предлагает рабочие места с различными требованиями к квалификации, в том числе и те, для которых наличие высшего 
образования и продвинутых компетенций не является преимуществом. Соответственно ситуация избыточного человеческого капитала на тех или иных производственных позициях для этих городов распространена в заметно меньшей степени. Например, на должностях служащих, не требующих высшего образования (офисные работники, лаборанты, библиотекари) доля закончивших вузы в столицах равна $4 \%$, а в населенных пунктах иных типов-10-13\%.

Таблица 4

Характеристики возможности в сферах получения образования и сохранения здоровья среди россиян из населенных пунктов разного типа,

ИС ФНИСЦ РАН, 2017 (\%)

\begin{tabular}{|c|c|c|c|c|c|}
\hline & 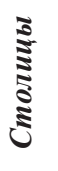 & 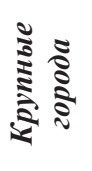 & 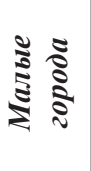 & 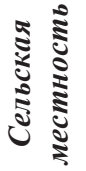 & 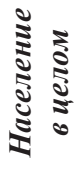 \\
\hline \multicolumn{6}{|l|}{ Возможности/позитивная привилегированность } \\
\hline $\begin{array}{l}\text { Возможность монополизировать приви- } \\
\text { легии социально привлекательных видов } \\
\text { образования }\end{array}$ & 19 & 27 & 23 & 23 & 24 \\
\hline $\begin{array}{l}\text { Доступность необходимых форм заботы } \\
\text { о здоровье }\end{array}$ & 9 & 10 & 9 & 10 & 9 \\
\hline $\begin{array}{l}\text { Навыки существования в цифровой } \\
\text { среде* }\end{array}$ & 35 & 31 & 25 & 23 & 27 \\
\hline \multicolumn{6}{|l|}{ Риски/негативная привилегированность } \\
\hline $\begin{array}{l}\text { Недоступность необходимого образова- } \\
\text { ния }\end{array}$ & 19 & 14 & 15 & 21 & 17 \\
\hline $\begin{array}{l}\text { Высокая вероятность значимого ухудше- } \\
\text { ния здоровья из-за объективных факто- } \\
\text { ров }\end{array}$ & 8 & 11 & 9 & 10 & 10 \\
\hline $\begin{array}{l}\text { Отсутствие доступа к ИКТ в повседнев- } \\
\text { ной жизни }\end{array}$ & 12 & 21 & 24 & 30 & 24 \\
\hline
\end{tabular}

* 2015 год

Риски и относительно низкие шансы населения в сфере сохранения здоровья и получения образования формируются за счет отсутствия доступа к инфокоммуникационным технологиям в повседневной жизни: $24 \%$ россиян не имеют устройств, позволяющих осуществлять выход в Интернет (компьютера, ноутбука, смартфона, планшета) и не владеют навыками соответствующей деятельности на работе. Несколько меньшую, но заметную роль 
в негативной привилегированности в этой сфере играет недоступность необходимого образования, а именно- «плохие» возможности получения такого образования или прекращение обучения до получения полного среднего образования (17\%), а также высокая вероятность ухудшения состояния здоровья в связи с ограниченными возможностями его поддержания, в частности- проблемами с получением необходимой медицинской помощи (10\%). Однако стоит отметить, что для всех населенных пунктов кроме столиц депривации в цифровой сфере наблюдаются в 1,5 раза чаще деприваций в сфере образования (табл. 4). При этом в Москве и Санкт-Петербурге соотношение носит обратный характер. Подобная ситуация является опять же спецификой жизни крупных населенных пунктов. Их инфраструктура развита хорошо и обеспечивает доступ к современным технологиям, а порой не оставляет возможностей ими не пользоваться. В то же время общий цейтнот ограничивает ресурс времени для дополнительного образования.

По совокупности имеющиеся риски и возможности россиян в сфере накопления человеческого капитала генерируют «отрыв» столиц от остального населения, который происходит в первую очередь за счет более активного укоренения цифровой коммуникации в жизни населения крупных городов. При этом стоит отметить, что навыки работы в цифровой среде востребованы не только рынком труда, где их отсутствие становится причиной проигрывания конкуренции. По мере цифровизации повседневно используемых сервисов и услуг (от госуслуг и заказа продуктов питания до онлайн обучения) и превращения интернета в ключевой источник информации соответствующие компетенции и возможности обеспечивают дополнительный и/или облегченный доступ к социально значимым благам и позволяют минимизировать издержки, как временные, так и финансовые.

\section{Заключение}

Общие жизненные шансы россиян формируются совокупностью рисков и возможностей, которые являются ограничениями и ресурсами их реакции на разные изменения или стимулы. В настоящий момент позитивная привилегированность населения обусловлена в основном относительно высокими возможностями потребления и досуга, а также экономическими условиями жизни: в этих сферах она распространена больше, чем негативная. При этом «подушка безопасности», способная обеспечить «страховку» на случай экономических шоков или выступить ресурсом для инвестиционных действий на микроуровне, формируется только у жителей Москвы и Санкт-Петербурга. Применительно к этим населенным пунктам можно говорить о локальном потенциале субъектов социальной политики микроуровня, которые имеют возможности решать хотя бы собственные проблемы социального и экономического характера. Расширение практик обеспечения экономической безопасности на нестоличные населенные пункты можно 
прогнозировать только после достижения товарного насыщения, которое еще не охватило большую часть страны. Ускорение этого процесса возможно при реализации социальной политики, направленной на воспитание культуры инвестиционно-ориентированного потребления. Среднесрочные перспективы страны зависят от населения средних возрастов, которое должно стать объектом социального инвестирования, в том числе через потребление товаров и услуг, повышающих комфортность повседневности и перспективы благополучия в будущем.

Ограниченные экономические возможности населения сопровождаются его негативной привилегированностью в производственной сфере, обусловленной повышенными рисками эксплуатации работодателями через нарушение базовых трудовых прав даже у столичных жителей. При этом возможности влиять на отдельные характеристики своего труда, которые есть у трети россиян, в большинстве случаев не могут выполнять роль эффективных стимулов для реализации человеческого потенциала страны. В наиболее уязвимом положении находятся при этом жители сельской местности. Ситуация эксплуатации работников в сфере производственных отношений, которая фиксируется последние годы, не только сопряжена с несправедливым или нелегитимным неравенством, но и снижает мотивацию работников к труду и инвестированию в собственный человеческий капитал, что в перспективе сужает «коридор возможностей» страны на пути социально-экономического развития. Поэтому государственная политика наращивания человеческого потенциала должна включать совершенствование трудового регулирования.

В сфере сохранения здоровья и повышения квалификации россияне зачастую ограничиваются освоением инфокоммуникационных технологий. Столицы при этом демонстрируют здесь заметный отрыв от остального населения. Возможности и навыки использования цифровых достижений в современном мире не только облегчают доступ к относительно благополучным рабочим местам, но и позволяют оптимизировать затраты ресурсов в повседневных практиках. Соответственно неравенство в освоении соответствующих технологий усугубляет существующие социально-экономические неравенства. В этой связи государственная политика, в том числе в части становления цифровой экономики, должна не только генерировать новые возможности для компетентных пользователей технологических достижений, но купировать драматическое отставание от них заметной доли населения (включая старшее поколение, жителей сельской местности, работников физического труда).

Отметим, что в выстраивании своих жизненных траекторий россияне в первую очередь фокусируются на потребительской составляющей, а возможности, связанные с инвестированием в различные сферы жизни и последующей капитализацией результатов этого инвестирования, пока остаются вне зоны внимания. Подобное смещение фокуса населения свидетельствует о его ограниченных возможностях встраиваться в технологичные сценарии развития страны, т.к. для соответствующих траекторий 
первоочередным является базирование экономики страны на человеческом капитале. Наиболее перспективными локациями при этом, являются столицы, но транслирование образцов их поведения вне сферы товарно-досугового потребления происходит с задержкой. В этих условиях возможности технологического развития напрямую зависят от того, насколько эффективна будет выстроена система социальной политики в области инвестирования в человеческий капитал.

\section{Выражение признательности}

Статья подготовлена в рамках проекта «Поведенческие стратегии населения в посткризисный период: как новые повседневные реалии жизни россиян скажутся на «коридоре возможностей» развития страны?», поддержанного Российским научным фондом, грант № 17-78-20125.

\section{Список источников}

Аникин В.А., Лежнина Ю.П. (2018) Экономическая стратификация: об определении границ доходных групп. Социологическое обозрение, 17 (1): 237-273.

Мареева С. В. (2016) Монетарные и немонетарные неравенства в жизни россиян. Соииологические исследования, (10): 65-74.

Овчарова Л.Н., Попова Д. О., Рудберг А.М. (2016) Декомпозиция факторов неравенства доходов в современной России. Журнал Новой экономической ассоциачии, 3 (31): 170-186.

Тихонова Н.Е. (2018) Стратификация по жизненным шансам массовых слоев современного российского общества. Социологические исследования, (6): 53-65.

Тихонова Н.Е., Давыдова Н. М., Попова И.П. (2004) Индекс уровня жизни и модель стратификации российского общества. Социологические исследования, (6): 120-129.

Anikin V. A., Lezhnina Y.P., Mareeva S., Tikhonova N.E. (2017) Social Stratification by Life Chances: Evidence from Russia. National Research University Higher School of Economics Series WP BRP 'Sociology', No. 80/SOC/2017.

Banerjee A.V., Duflo E. (2008) What is middle class about the middle classes around the world? The Journal of Economic Perspectives: A Journal of the American Economic Association, 22 (2): 3-28.

Beck U. (2009) World at risk. Cambridge: Polity.

Breen R. (2005) Foundations of a neo-Weberian class analysis. E. O. Wright (ed.) Approaches to Class Analysis. Cambridge: Cambridge University Press: 31-50.

Credit Suisse Research Institute (2015) Global Wealth Report. Доступно по ссылке: https://publications.credit-suisse.com/tasks/render/file/?fileID=F2425415-DCA7-80B8-EAD989AF9341D47E (дата обращения 24 марта 2018).

Eitzen D. S., Zinn M.B. (1989) The Reshaping of America: Social Consequences of the Changing Economy. Englewood Cliffs: Prentice Hall.

Giddens A. (1973) The Class Structure of the Advanced Societies. London: Hutchinson.

Goldthorpe J.H., Llewellyn C., Payne C. (1987) Social mobility and class structure in modern Britain. 2nd ed. Oxford: Clarendon Press.

Popova D., Pishnyak A. (2017) Measuring individual material well-being using multidimensional indices: an application using the Gender and Generation Survey for Russia. Social Indicators Research, 130 (3): 883-910.

Robeyns I., Brighouse H. (eds.) (2010) Measuring justice primary goods and capabilities. Cambridge: Cambridge University Press.

Scott J. (2002) Social class and stratification in late modernity. Acta Sociologica, 45 (1): 23-35.

Sen A. (1992) Inequality reexamined. New York: Russell Sage Foundation.

Weber M. (1978) Economy and Society: An Outline of Interpretive Sociology. Berkley: University of California Press. 
Yulia Lezhnina

\title{
THE RISKS AND CAPABILITIES OF RUSSIANS AS A BASE FOR SOCIAL DYNAMICS
}

\begin{abstract}
One of the central questions of social policy is control over the level and depth of inequality. The simplest, and therefore most common, means for measuring its variation is differentiating the incomes of the population. However, studying social inequality also requires an assessment of the risks and life chances among the population through access to socially valuable benefits and resources. It is these elements that generate life options, which require either instruments of compensation or open up a new window of opportunities. This article is based on representative surveys from Institute of Sociology at the Russian Academy of Sciences. It uses a Weberian logic of life chances and negative/positive privileges. This allows an examination of the main risks and opportunities of the Russian population in terms of (1) economic living conditions, (2) consumption and leisure patterns, (3) situations at work, (4) educational opportunities and health maintenance. What is shown is that positive privilege is mainly obtained through consumption and economic conditions while negative privilege is about the condition of Russians in the industrial sphere. Such life conditions in the population reflect limitations in technological capacities for the country's development, where human capital is the main form of production. Those living in Russia's 'capitals' (Moscow and St. Petersburg) have absorbed consumer practices that differ strongly from the rest of the country, which only imitates these forms of behaviour. The next area that Russians are learning is skills for surviving in the digital age. Even the inhabitants of Russia's capitals face risks, as do the rest of the population, that limit the positive dynamics of human capital potential in the country's future. Negative privilege is most commonly localised in rural areas, while in the industrial sector it has even become a commonplace way of life.
\end{abstract}

Keywords: life-chances, capabilities, risks, opportunities, spatial inequality

DOI: 10.17323/727-0634-2019-17-2-207-222

\section{References}

Anikin V.A., Lezhnina Yu.P. (2018) Ekonomicheskaya stratifikatsiya: ob opredelenii granits dokhodnykh grupp [Income Stratification: Putting a Spotlight on the Boundaries]. Sociologicheskoe obozrenie [Russian Sociological Review], 17 (1): 237-273.

Yulia P. Lezhnina- Candidate of Science in Sociology, Senior Researcher, Institute for Social Policy, National Research University Higher School of Economics; Senior Researcher; Institute of Sociology, Russian Academy of Science, Moscow, Russian Federation. Email: lezhnina@list.ru 
Anikin V.A., Lezhnina Y.P., Mareeva S., Tikhonova N.E. (2017) Social Stratification by Life Chances: Evidence from Russia. National Research University 'Higher School of Economics' Series WP BRP 'Sociology', 80/SOC/2017.

Banerjee A. V., Duflo E. (2008) What is Middle Class about the Middle Classes around the World? The Journal of Economic Perspectives: A Journal of the American Economic Association, 22 (2): 3-28.

Beck U. (2009) World at Risk. Cambridge: Polity.

Breen R. (2005) Foundations of a neo-Weberian Class Analysis. In: E. O. Wright (ed.) Approaches to Class Analysis. Cambridge: Cambridge University Press: 31-50.

Credit Suisse Research Institute (2015) Global Wealth Report. Available at: https://www. credit-suisse.com/corporate/en/research/research-institute/global-wealth-report.html (accessed 24 March 2018).

Eitzen D. S., Zinn M. B. (1989) The Reshaping of America: Social Consequences of the Changing Economy. Englewood Cliffs: Prentice Hall.

Giddens A. (1973) The Class Structure of the Advanced Societies. London: Hutchinson.

Goldthorpe J.H., Llewellyn C., Payne C. (1987) Social mobility and Class Structure in Modern Britain. $2^{\text {nd }}$ ed. Oxford: Clarendon Press.

Mareeva S. V. (2016) Monetarnye i nemonetarnye neravenstva $v$ zhizni rossijan [Monetary and Non-monetary Inequalities in Life of Russians]. Sociologicheskie issledovanija [Sociological Studies], (10): 65-74.

Ovcharova L. N., Popova D. O., Rudberg A.M. (2016) Dekompozicija faktorov neravenstva dohodov v sovremennoj Rossii [Decomposition of Income Inequalities Factors in Modern Russia]. Zhurnal novoj jekonomicheskoj associacii [The Journal of the New Economic Association], 3 (31): 170-186.

Popova D., Pishnyak A. (2017) Measuring Individual Material Well-being Using Multidimensional Indices: An Application using the Gender and Generation Survey for Russia. Social Indicators Research, 130 (3): 883-910.

Robeyns I., Brighouse H. (eds.) (2010) Measuring Justice Primary Goods and Capabilities. Cambridge: Cambridge University Press.

Scott J. (2002) Social Class and Stratification in Late Modernity. Acta Sociologica, 45 (1): $23-35$.

Sen A. (1992) Inequality Reexamined. New York, NY: Russell Sage Foundation.

Tihonova N.E. (2018) Stratifikacija po zhiznennym shansam massovyh sloev sovremennogo rossijskogo obshhestva [Stratification by Life Chances of Mass Strata of Modern Russian Society]. Sociologicheskie issledovanija [Sociological Studies], (6): 53-65.

Tihonova N.E., Davydova N. M., Popova.I.P. (2004) Indeks urovnja zhizni i model' stratifikacii rossijskogo obshhestva [The Standard of Living and the Stratification Model of Russian Society]. Sociologicheskie issledovanija [Sociological Studies], (6): 120-129.

Weber M. (1978) Economy and Society: An Outline of Interpretive Sociology. Berkley: University of California Press. 